\title{
Current status and strategies for hepatitis B control in Korea
}

\author{
Eun Ju Cho', Sung Eun Kim², Ki Tae Suk ${ }^{3}$, Jihyun $\mathrm{An}^{4}$, Soung Won Jeong ${ }^{5}$, Woo Jin Chung ${ }^{6}$, and Yoon Jun Kim \\ 'Department of Internal Medicine and Liver Research Institute, Seoul National University College of Medicine; ${ }^{2}$ Department of Internal \\ Medicine, Hallym University Sacred Heart Hospital, Hallym University College of Medicine, Anyang; ${ }^{3}$ Department of Internal Medicine, \\ Hallym University College of Medicine, Chuncheon; ${ }^{4}$ Asan Medical Center, University of Ulsan College of Medicine, Seoul; ${ }^{5}$ Department \\ of Internal Medicine, Soonchunhyang University Hospital, Seoul; 6Department of Internal Medicine, Keimyung University School of \\ Medicine, Daegu, Korea.
}

\begin{abstract}
Hepatitis B virus (HBV) infection is the most common cause of chronic liver diseases in Korea. After the introduction of the universal HBV vaccination program, the prevalence of hepatitis B surface antigen was markedly reduced, and Korea is now classified as an area of intermediate endemicity for HBV. However, there are still hurdles for elimination of hepatitis B, such as immunoprophylaxis failure against vertical transmission, occurrence of acute hepatitis $B$ among peoples who did not have vaccination at younger age, and rapid increase of immigrant populations from HBV endemic areas. To achieve the World Health Organization goal of viral hepatitis elimination by 2030 in Korea, we suggest comprehensive policies for more effective control of hepatitis $B$ as following: i) insurance coverage for antiviral prophylaxis in mothers with high viremia, ii) screening for hepatitis B seromarkers and catch-up HBV vaccinations of susceptible persons with hepatitis $B$, iii) establishment of an independent 'viral hepatitis sector' in Centers for Disease Control \& Prevention to organize and execute comprehensive strategy for management of viral hepatitis, iv) encourage of management of HBV infection in immigrant populations, v) national campaign to promote awareness of hepatitis B. (Clin Mol Hepatol 2017;23:205-211)

Keywords: Viral hepatitis; Hepatitis B; Korea
\end{abstract}

\section{INTRODUCTION}

Hepatitis B virus (HBV) infection is an important public health problem worldwide and a major cause of chronic hepatitis, cirrhosis, and hepatocellular carcinoma. ${ }^{1}$ Although the prevalence of chronic HBV infection is decreasing in Korea as a result of the $H B V$ vaccination program, it is still a major cause of liver-related morbidity and mortality. This review describes an overview of changing epidemiology of HBV infection in Korea, current strate- gies for control of hepatitis B, and policy proposals to eradicate hepatitis $B$.

\section{CURRENT STATUS OF HEPATITIS B IN KOREA}

\section{Prevalence of hepatitis B virus infection in Korea}

Before the introduction of the hepatitis B virus (HBV) vaccine,

\section{Abbreviations:}

HBV, hepatitis B virus; HBsAg, hepatitis B surface antigen; $\mathrm{HBIG}$, hepatitis B immunoglobulin

\section{Corresponding author : Yoon Jun Kim}

Department of Internal Medicine and Liver Research Institute, Seoul National University Hospital, 101 Daehak-ro, Jongno-gu, Seoul 03080, Korea.

Tel: +82-2-2072-3081, Fax: +82-2-743-6701

E-mail:yoonjun@snu.ac.kr

http://orcid.org/0000-0001-9141-7773 


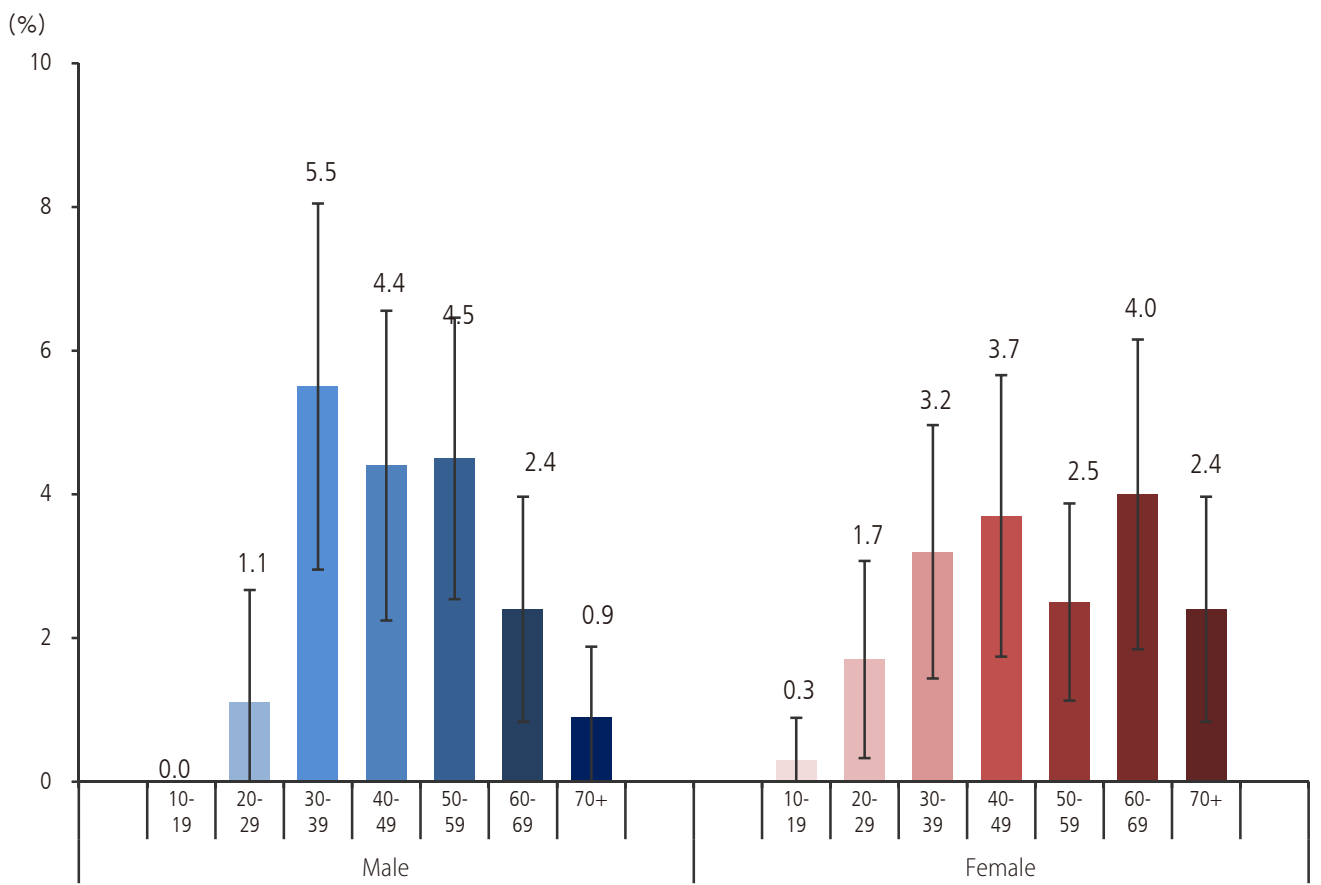

Figure 1. Prevalence of HBsAg by age and sex group. Adopted from Korean $\mathrm{Na}$ tional Health and Nutritional Examination Survey in 2014. the prevalence of HBV carriage ranged from 8-10\% in the 1980s and early 1990 s. $^{2}$ After the launch of the universal vaccination program, the overall prevalence of hepatitis B surface antigen (HBsAg) has decreased from $4.6 \%$ in 1998 to $2.9 \%$ in 2008 , and has been maintained at $2.9 \%$ since 2013 without significant changes. The rates of HBsAg carriage were consistently higher in males than in females, but the difference gradually decreased from $1.1 \%$ in 1998 , to $0.5 \%$ in 2014 . The rates peaked in 1998 among individuals between the ages of 35-39 years, whilst in 2013, individuals between the ages of 50-54 years recorded the highest rates. Specifically, the rates of HBsAg carriage in subjects $>10$ years old decreased from $4.6 \%$ in 1998 (5.1\% in males and $4.0 \%$ in females), to $2.9 \%$ in 2013 (3.1\% in males and $2.5 \%$ in females). In 2014, the rates were lowest in subjects aged 10-29 years, with $<1 \%$ for subjects between 10-19 years old and around $1 \%$ for subjects between $20-29$ years old. The highest rates were observed in males aged $30-59$ years (4-5\%), and females aged 60 69 years (4\%) (Fig. 1). In the assessment of pediatric and adolescent population, subjects between the ages of 10-19 years showed seropositive rates of $2.2 \pm 0.4 \%$ in $1998,1.9 \pm 0.5 \%$ in $2001,1.9 \pm 0.7 \%$ in $2007,0.2 \pm 0.1 \%$ in $2009,0.1 \pm 0.1 \%$ in 2011 , and $0.4 \pm 0.4 \%$ in 2013 , showing significant reduction over time $(P<0.001)$.

According to the 2009 census performed in 290,212 individuals of age and gender-standardized population, significant regional variation appeared. Seropositive rates were higher in Jeju island, Kwangju, Jeonnam, Busan, and Kyungnam (Fig. 2).

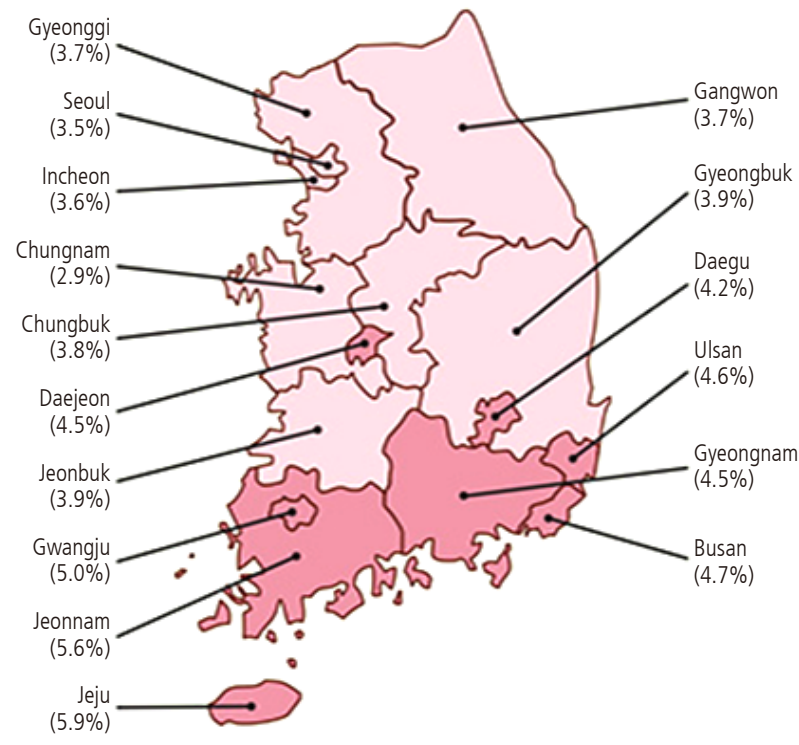

Figure 2. A nationwide seroprevalence of HBsAg in 2009, Korea. Presented in 18th annual meeting of the Korean Association for the study of the Liver.

\section{Incidence of acute hepatitis B}

Since 2006, acute hepatitis B has been categorized as a group 2 nationally notifiable infectious diseases, and the monitoring system has been changed from a sentinel monitoring system to a mandatory surveillance system since 2010. In the 1980s, about $60 \%$ of patients with acute viral hepatitis were infected with 
Table 1. Annual incidence of HBV infection

\begin{tabular}{|c|c|c|c|c|c|c|c|c|c|c|c|c|}
\hline Annual incidence & 2004 & 2005 & 2006 & 2007 & 2008 & 2009 & 2010 & 2011 & 2012 & 2013 & 2014 & 2015 \\
\hline Acute hepatitis B & 537 & 650 & 1,211 & 1,588 & 1,612 & 1,746 & 1,486 & 462 & 303 & 117 & 173 & 155 \\
\hline $\begin{array}{l}\text { HBsAg-positive pregnant } \\
\text { women }\end{array}$ & 9,192 & 7,339 & 6,985 & 6,980 & 5,584 & 3,813 & 3,581 & 936 & 2,428 & 3,211 & 3,912 & 3,468 \\
\hline Vertical transmission & 2 & 9 & 18 & 6 & 6 & 7 & 18 & 30 & 26 & 59 & 30 & 43 \\
\hline
\end{tabular}

Source: Korea Centers for Disease Control and Prevention (2015).

$H B V$, hepatitis B virus.

Table 2. Prevalence of hepatitis B in foreign workers

\begin{tabular}{|c|c|c|c|c|c|c|c|c|c|c|}
\hline \multirow{2}{*}{ Nation } & \multicolumn{2}{|c|}{$\begin{array}{l}\text { According to the } \\
\text { literature }\end{array}$} & \multicolumn{2}{|c|}{2010} & \multicolumn{2}{|c|}{2011} & \multicolumn{2}{|c|}{2012} & \multicolumn{2}{|c|}{2013} \\
\hline & HBV & $\mathrm{HCV}$ & HBV & $\mathrm{HCV}$ & HBV & $\mathrm{HCV}$ & HBV & $\mathrm{HCV}$ & HBV & $\mathrm{HCV}$ \\
\hline Chinese & $7.18 \%$ & $0.43 \%$ & $7.8 \%$ & $11.2 \%$ & & & $13.3 \%$ & $6.7 \%$ & & \\
\hline Mongolia & $11.8 \%$ & $15 \%$ & & & $10.6 \%$ & $9.1 \%$ & $9.1 \%$ & $4.5 \%$ & $10.3 \%$ & $8.9 \%$ \\
\hline
\end{tabular}

Adopted from White paper on liver disease in Korea, 2013.

$\mathrm{HBV}$, hepatitis B virus; $\mathrm{HCV}$, hepatitis C virus.

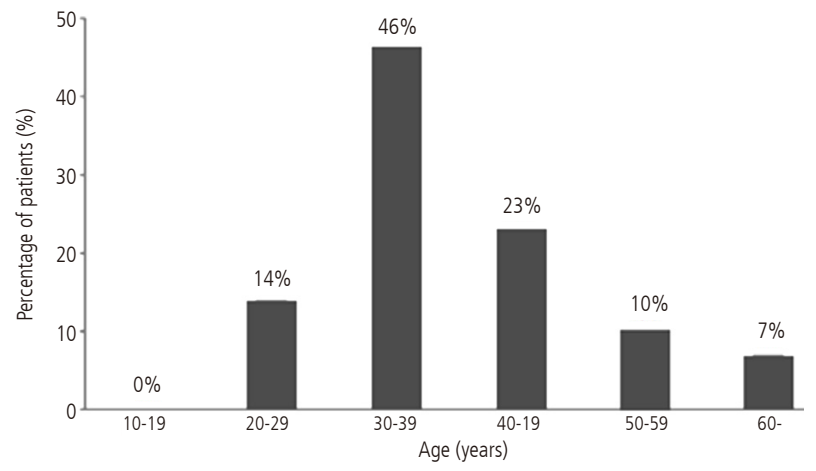

Figure 3. Age distribution of acute hepatitis B. Adopted from the Korean Journal of Hepatology; $2011 .{ }^{5}$

$\mathrm{HBV}^{3}{ }^{3}$ This has decreased to approximately $5 \%$ of recent acute viral hepatitis cases in Korean adults, ${ }^{4}$ and the occurrence of acute hepatitis B has consistently decreased (Table 1). Most of the acute hepatitis B patients in the early 1980s were aged 10-29 years. Recently, acute hepatitis B occurs in subjects aged 30-40 years, who were born before the introduction of the HBV vaccination program (Fig. 3). ${ }^{5}$ Because transverse transmission of HBV may still occur in unvaccinated and uninfected adults, an adult without a complete set of previous vaccinations should be given 'catch-up' $H B V$ vaccinations to prevent acute $H B V$ infection.

\section{Prevalence of HBV infection in a specific population}

According to a report from Hanawon, the Unification Ministry's half-way house, 669 of 6,087 (10.9\%) North Korean defectors were diagnosed with hepatitis $B$ during routine health checkup. Considering that the seroprevalence of HBsAg in the South Korean at a similar period was around $4 \%$, the management of hepatitis B in North Korea may be poor. Meanwhile, according to results of the free health checkup offered to foreign workers during the "Liver Day" event hosted by the Korean Association for the Study of the Liver and Korean Liver Foundation, the seroprevalence of HBV and HCV significantly differed between countries; specifically, Chinese and Mongolian workers had higher prevalence of hepatitis B (Table 2). Because illegal residents / foreign workers, unlike those who are legally admitted, undergo no medical screening, the rapidly increasing population of illegal aliens has also set off a resurgence of contagious diseases such as hepatitis B. Therefore, it is necessary to ensure that everyone has access to basic medical care, not only to ensure adherence to basic human rights, but also for public health.

\section{CURRENT STRATEGIES FOR CONTROL OF HEPATITIS B}

\section{Prevention of perinatal infection}

Hepatitis B is most commonly spread from mother-to-child transmission in highly endemic areas. During the 1980s, about $11 \%$ of neonates in Korea were infected with HBV via vertical 


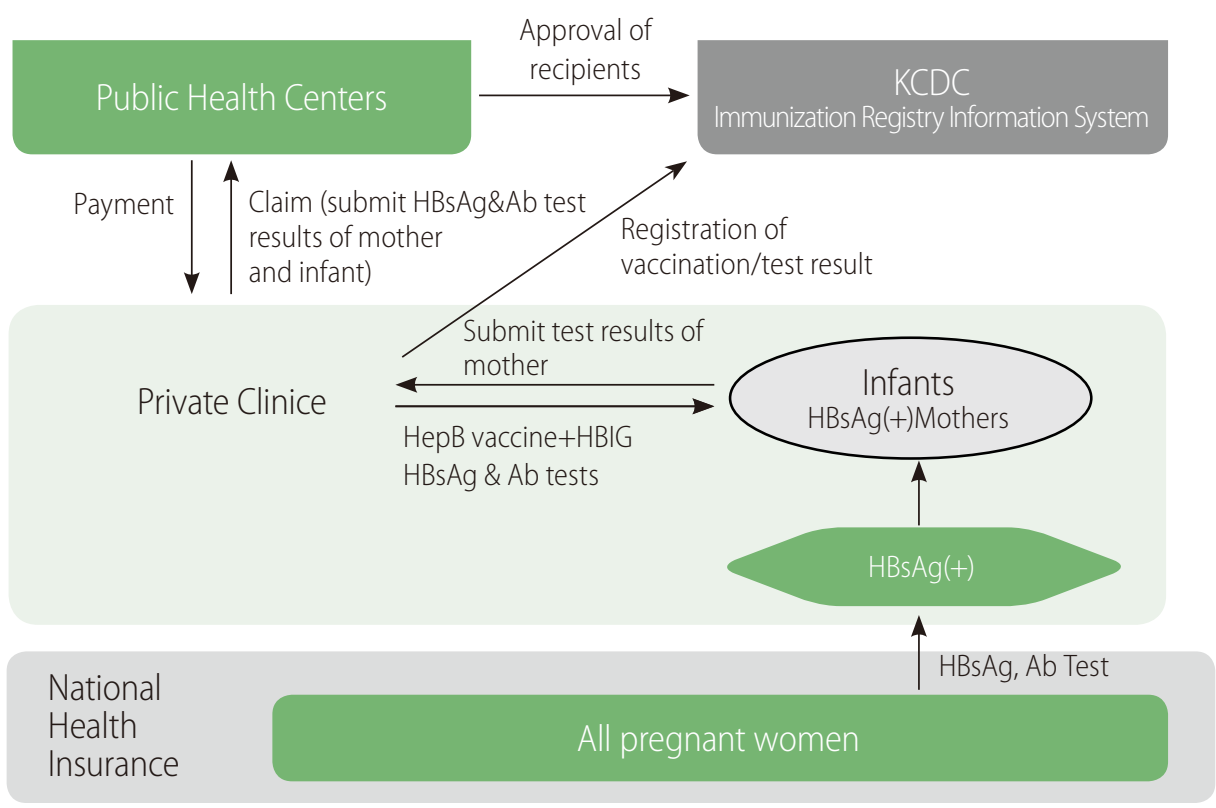

Figure 4. Korean program for implementing perinatal transmission prevention. Source: Korea Centers for Disease Control and Prevention (2016).

Table 3. Results of hepatitis B serologic test (from July 2002 to December 2014)

\begin{tabular}{llcc}
\hline & Test results & Number of persons & Rates (\%) \\
\hline Immunoprophylaxis success (97.1\%) & HBsAg (-) /anti-HBs Ab(+) & 84,201 & 85.7 \\
Immunoprophylaxis failure (2.9\%) & $\mathrm{HBsAg}(-) /$ anti-HBs Ab(-) & 11,214 & 11.4 \\
& $\mathrm{HBsAg}(+)$ /anti-HBs Ab(-) & 2,674 & 1.7 \\
\hline
\end{tabular}

Source: Korea Centers for Disease Control and Prevention (2016).

transmission. Particularly, the vast majority (i.e. 65-93\%) of unvaccinated infants born to hepatitis $B$ e antigen-positive mothers became infected. ${ }^{2}$ Therefore, the Ministry of Health and Welfare and Korea Centers for Disease Control and Prevention have been organizing HBV vertical transmission prevention program since July 2002, which provides complete financial support for HBV vaccination and tests for newborns from HBsAg-positive mothers. All pregnant women check for HBsAg prior to delivery, and infants born to carrier mothers receive hepatitis B immunoglobulin (HBIG) at birth; HBV vaccination at birth and at 1 and 6 months of age; and test for $\mathrm{HBsAg}$ and antibody to $\mathrm{HBsAg}$ at 9-15 months of age (Fig. 4). The mothers submit the health checks to clinics, and the clinics submit the serologic test results of mothers and infants to public health centers. The results were forwarded to the Immunization Registry Information System, where the details were used to manage the program and measure compliance.

Through these endeavor, 180,690 out of 188,224 newborns ( $96 \%)$ born to carrier mothers participated in the prevention program between July 2002 and December 2014. Of them, 84,000 ( 85.7\%) newborns had completed the 3-dose vaccination regimen and acquired immunity (Table 3 ). The completion rate has increased from $92.9 \%$ in 2008 , to $99.4 \%$ in 2013 , and the rate of possible HBV infection decreased about $93 \%$. The seroprevalance of $\mathrm{HBsAg}$ has remarkably reduced to $\sim 3.1 \%$ in individuals $>10$ years old, and to $0.2 \%$ in $4-6$ years old infants (Fig. 5), which implies that perinatal transmission, the most important route of HBV infection in Korea, may continue to decrease.

\section{POLICY PROPOSALS TO ERADICATE HEPATITIS B IN KOREA}

\section{Antiviral therapy in pregnant women with high viremia}

Although the combination of passive and active immunization 


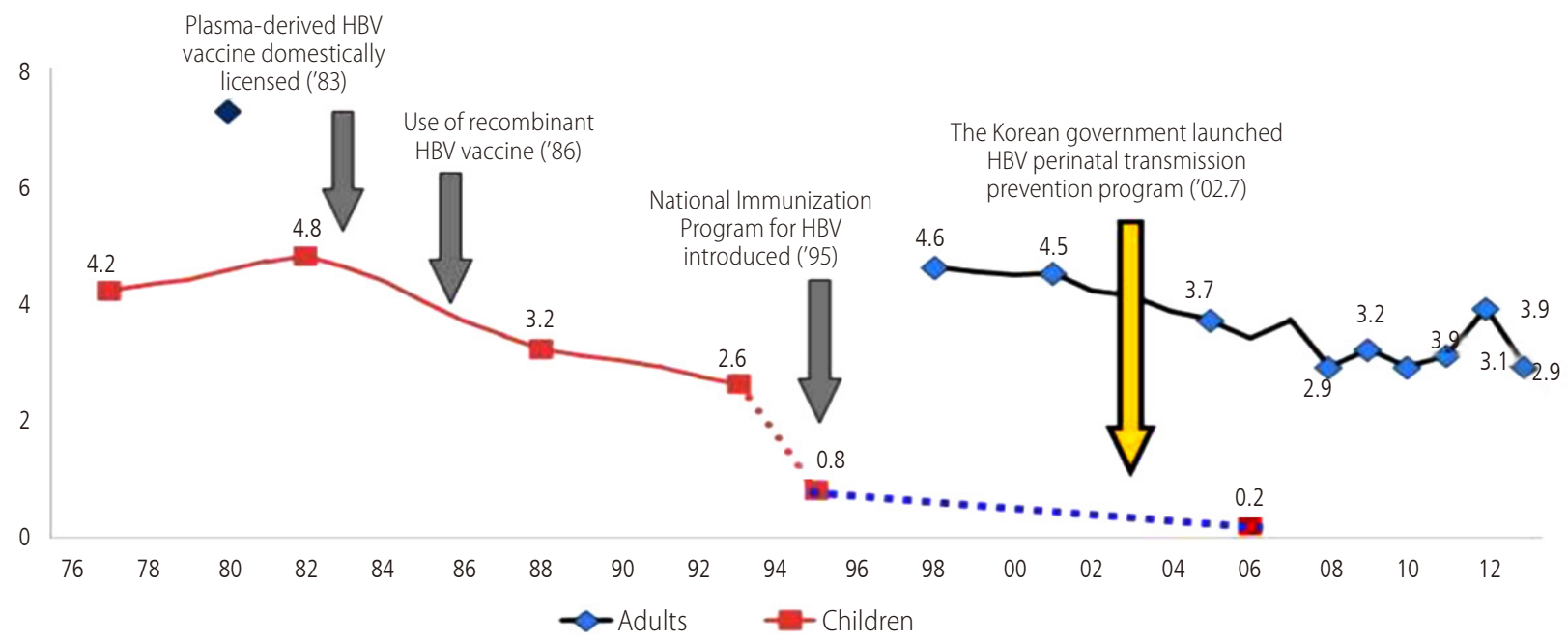

Figure 5. Trends in the prevalence of HBV infection according to implementation of national HBV vaccination program. Source: Korea Centers for Disease Control and Prevention (2016). HBV, hepatitis B virus.

reduces the vertical transmission rate from $90 \%$ to $10 \%$, immunoprophylaxis fails in 10 to $30 \%$ of infants born to mothers with serum HBV DNA levels $>10^{6} \mathrm{IU} / \mathrm{mL} .^{6,7}$ Recent large-scale study showed that tenofovir treatment during the third trimester could reduce the maternal viral load and prevent vertical transmission of HBV. ${ }^{8}$ Thus, mothers with high levels of HBV DNA should be informed that utilizing a prophylactic antiviral therapy could add to the effectiveness of HBIG and vaccination. However, current health insurance systems do not cover antiviral therapy in this situation. To solve the problem, antiviral therapy for mothers with high viremia in third trimester should be covered by the insurance.

\section{Catch-up vaccination}

Conventionally, catch-up vaccination for unprotected population has not been involved in the national policy to control hepatitis B. However, acute HBV infection sporadically occurs among adolescents and adults who did not have vaccination at younger age. Therefore, it is necessary to assess the prevalence of $\mathrm{HBs} A \mathrm{Ag}$, and age groups with $\mathrm{HBsAg-positive} \mathrm{rate}>1 \%$. For example, in the U.S., HBV infection rates were high for infants of mothers who had migrated from high level or intermediate level endemic areas (such as Alaska or islands in Pacific Ocean). For them, additional guideline were established and catch-up vaccinations for 11-12 years old adolescents, and high-risk adults were provided. In Alaska, universal infant vaccination coupled with population-wide screening and vaccination for susceptible persons has eliminated $\mathrm{HCC}$ and acute symptomatic HBV infection. ${ }^{9}$ With an increasing number of North Korean defectors, catch-up vaccination for susceptible persons could be an effective method to prevent additional HBV transmission.

In addition, mass screening for hepatitis B seromarkers is warranted. Even in the cases of successful prevention of perinatal infection, there is still a risk of HBV infection during the transition to adulthood. According to the 'Outbreak report of nationally notifiable infectious diseases by the Ministry of Health and Welfare, acute HBV infection still occurs among adolescents and adults due to sexual contact, parenteral drug use, receipt of blood products, dialysis, and occupational exposures. Thus, appropriate education about high-risk behaviors and immunization of susceptible persons with hepatitis B may be needed to prevent new HBV infections.

\section{Integrated control of hepatitis B by the establishment of national center for viral hepatitis}

Currently, five independent parts at Centers for Disease Control \& Prevention are involved in managing viral hepatitis, and there is no control center; therefore, an integrated and effective management of viral hepatitis is not feasible. National health plans should provide the overall strategic direction for the health sector. It is important that specific planning for priority areas, such as vaccination program, management of HBV-related disease, epidemiologic investigation, and research of viral hepatitis, is aligned with national health plans. However, there is often a disconnection between planning for center-specific programs and national strategies which are often performed by different constituencies. This leads to frag- 
mentation and increased costs in the implementation of programs. Therefore, it is important to integrate disease-specific plan in national health plans, and integrate disease-specific services within the currently available health services. To achieve the goal of viral hepatitis elimination by 2030 in Korea, establishment of an independent 'viral hepatitis sector' in Centers for Disease Control \& Prevention is needed to organize and execute comprehensive strategy for the management of the viral hepatitis.

\section{Management of HBV infection in immigrant populations}

Rapid increase in international migration is a worldwide trend. Mobile populations present unique health care concerns for society. In many developed countries, immigrants from high endemic areas may be partly related to an increasing burden of chronic HBV infection.

For a long time, Koreans had little experience with other ethnic groups. Recently, the sudden influx of foreign workers and increasing number of international marriage imposes challenges for both Koreans and migrants, heightening the risk for HBV infection. According to monthly statistics published by the Ministry of Justice and Korea Immigration Service in 2015, the number of foreigners as of January 2015 was 1,774,603. More than half of them came from HBV endemic areas such as Chinese $(918,951$, $51.8 \%)$, Vietnam (129,423, 7.3\%), Philippines (51,836, 2.9\%), and Indonesia (42,520, 2.4\%). Furthermore, according to health check supported by the Ministry of Health and Welfare in 2008, about 40 to $60 \%$ of immigrants wives were susceptible to HBV infection. ${ }^{10}$ However, available resources for HBV prevention and care are targeted to Koreans, and migrants have little access to health services. According to the 'Survey on labor rights of migrant workers' by the Joint Committee with Migration in Korea, $80.9 \%$ of the workers were working over 10 hours a day, and 31.9\% were working 12 hours a day. Among them, only 27\% had regular health check as most of the workers could not spare time during the day time. In most cases, the workers visited the free clinics for migrant workers on Sunday, or waited until the symptoms worsened. In addition to structural problems, cultural and linguistic barriers also limit accessibility, and the illegal status of workers may cause them to actively avoid government health services. Therefore, the assessment of health conditions for future immigrants is an important issue waiting for the government's attention. Children of foreigners must also be included in intervention activities for preventing perinatal infection. Even unregistered foreigners should be able to ob- tain financial aid for health care. Active promotion of these programs will reduce the spread of hepatitis B in Korea.

\section{National campaigns to promote awareness of hepatitis B}

Typically, the public perception of hepatitis B is comparably higher than that of other viral hepatitis. However, the level of awareness is still low in Korean population. Campaigns to raise awareness about viral hepatitis among policy-makers and the public and strengthening prevention measures are the most expedient ways to educate people on the high burden of HBV-related diseases, the need for prevention of transmission, and importance of maintaining healthy life-style. National efforts to raise awareness and understanding of viral hepatitis should be performed consistently.

\section{SUMMARY}

HBV infection is still a serious public health problem in Korea. To achieve the goal of eliminating hepatitis B by 2030 in South Korea, comprehensive national action plans for prevention, screening, diagnosis and treatment of hepatitis B should be developed through consultation between governments, health providers and society. In addition, greater investment will be needed in public health research to maximize the costeffectiveness of national action plans.

\section{Conflicts of Interest}

The authors have no conflicts to disclose.

\section{Funding support}

This research was supposed by a fund (4851-308-260-01) by Research of Korea Centers for Disease Control and Prevention.

\section{REFERENCES}

1. Nelson NP, Easterbrook PJ, McMahon BJ. Epidemiology of Hepatitis B Virus Infection and Impact of Vaccination on Disease. Clin Liver Dis 2016;20:607-628.

2. Park NH, Chung YH, Lee HS. Impacts of vaccination on hepatitis B viral infections in Korea over a 25-year period. Intervirology 2010;53:20-28.

3. Lee HS, Byun JH, Kim CY. Etiology and outcome of acute viral hepa- 
titis in Korean adults. J Korean Med Sci 1990;5:149-154.

4. Jang JH, Jung YM, Kim JS, Lee SH, Kim JW, Hwang SG, et al. Coexistence of $\lg M$ antihepatitis $A$ virus and $\lg M$ antihepatitis $E$ virus in acute viral hepatitis: a prospective, multicentre study in Korea. J Viral Hepat 2011;18:e408-e414.

5. Choi HJ, Ko SY, Choe WH, Seo YS, Kim JH, Byun KS, et al. Clinical features of acute viral hepatitis B in Korea: a multi-center study. Korean J Hepatol 2011;17:307-312.

6. Zhang H, Pan CQ, Pang Q, Tian R, Yan M, Liu X. Telbivudine or lamivudine use in late pregnancy safely reduces perinatal transmission of hepatitis B virus in real-life practice. Hepatology 2014 Jan 27. [Epub ahead of print]

7. Xu WM, Cui YT, Wang L, Yang H, Liang ZQ, Li XM, et al. Lamivudine in late pregnancy to prevent perinatal transmission of hepatitis B virus infection: a multicentre, randomized, double-blind, placebocontrolled study. J Viral Hepat 2009;16:94-103.

8. Pan CQ, Duan Z, Dai E, Zhang S, Han G, Wang Y, et al. Tenofovir to Prevent Hepatitis B Transmission in Mothers with High Viral Load. N Engl J Med 2016;374:2324-2334.

9. McMahon BJ, Bulkow LR, Singleton RJ, Williams J, Snowball M, Homan $C$, et al. Elimination of hepatocellular carcinoma and acute hepatitis B in children 25 years after a hepatitis B newborn and catch-up immunization program. Hepatology 2011;54:801-807.

10. Kim HK, Yoo SH, Cho S, Kwon EJ, Kim SY, Park JY. Health status and associated health risks among female marriage immigrants in Korea. Korean J Health Educ Promot 2010;27:79-89. 